Article

\title{
A Research on the Combination of Oblique Photography and Mobile Applications Based on the Sustainable Development of Tourism
}

\author{
Mengyi Lin ${ }^{1}$, Fu-Yuan $\mathrm{Li}^{2}{ }^{2 *}$ and Haibin $\mathrm{Zhou}^{3}$ \\ 1 The Graduate Institute of Design Science, Tatung University, Taipei 104, Taiwan; d10517014@ms.ttu.edu.tw \\ 2 Department of Industrial Design, Tatung University, Taipei 104, Taiwan \\ 3 Academy of Art Design, Fujian Business University, Fuzhou 350012, China; bingo353416@fjbu.edu.cn \\ * Correspondence: richardlee@gm.ttu.edu.tw; Tel.: +886-931-216524
}

Received: 22 March 2020; Accepted: 21 April 2020; Published: 25 April 2020

\begin{abstract}
Tourism is one of the world's fastest driving forces of economic development, playing an important role in achieving sustainable development goals. In modern society, mobile social media is a communication and decision-making platform for users and a source of big data information about travel. Obtaining and analyzing travel data can provide customer-oriented information about travel destinations and comprehensive services for both tourism operators and tourists. It has a positive impact on the sustainable development of society, economy, environment, and humanities. Starting with theoretical analysis and empirical research, this study combines social media and oblique photography, conducts a case study of the Pingtan comprehensive experimental area in China, and develops an app about online travelling to provide corresponding information for consumers' decisions. This study also discusses the potential value of the app, i.e., assisting the development of smart travel in city, achieving sustainable development of tourism, and contributing to tourism globally.
\end{abstract}

Keywords: sustainable tourism; oblique photography; mobile applications; social media

\section{Introduction}

Global tourism has shown a rapid growth trend, which has been affected by the emergence of digitization and internet service. The continuous growth of the tourism industry has made it a major industry in the world economy. It has also drawn great attention from researchers, especially in the field of sustainable tourism [1]. The United Nation (UN) member states proposed the 2030 Agenda for Sustainable Development in 2015, pointing out a shared blueprint of peace and prosperity for the present and the future of human beings and the planet [2]. Sustainable tourism has been marked as having a potentially valuable role in achieving "sustainable development goals": "Tourism has the potential to contribute directly or indirectly to all goals. In particular, it has been included as targets in Goals 8, 12, and 14 on inclusive and sustainable economic growth, sustainable consumption/production (SCP), and the sustainable use of oceans and marine resources, respectively." In 2019, the contribution of China's tourism to its GDP was 10.94 trillion-yuan, accounting for $11.05 \%$ of the total GDP. Tourism directly and indirectly employed 79.87 million people, accounting for $10.31 \%$ of the total employed population of the country. [3] China is also striving to become a smart and sustainable tourist destination. In fact, the sustainability of tourist destinations has become a key factor for improving competitiveness [4]. Therefore, how to carry out the marketing plan to improve the core competitiveness of tourist destinations and at the same time balance the ecology of tourist destinations to achieve sustainable and coordinated development becomes particularly important. In recent years, 
the rapid development of smart technologies and informatization of tourism have assisted operators to make full use of technology to inform tourists about tourist destinations (especially available services), making tourist destinations smart and sustainable, providing tourists with high-quality tourism services, benefiting the tourism industry, and improving the quality of life for local people [5].

Previous surveys show that tourism is a complicated industry. Statistics, information, and knowledge from or about tourists are the essential basis of the competition and innovation on tourist destination [6,7]. They enable people to obtain detailed information about tourism, including the general understanding of local people, such as their preferences, feelings, and attitudes. These data are useful for creating tourism services that better meet the demands of tourists [8]. With the expansion of online travel applications (apps), consumer data will be enriched and easier to access, the information will be timely and accurately touched, and the capacity of data analysis will be improved to support the analysis of market behavior and consumer behavior motivation. Thus far, there are only a few papers about how tourist destination managers and tourism organizations can take advantage of the massive information generated by tourists in the travel experience to achieve a more effective process of value creation, especially those in information access and between valuable and uncertain targeting managers and entrepreneurs [9-13]. Although several tycoons in the tourism industry, such as Ctrip and Qunar.com, have issued multiple reports on tourism consumption each year to provide direction for the research of tourism market demand and tourists' consumption concept, it is difficult for managers to create a large database to analyze a specific tourist destination. Most tourism apps feature a comprehensive collection of tourism information throughout the country and provide standardized tourism services, while tourists are increasingly interested in various commodities and diverse services featured with local characteristics of a certain tourist destination. In the past, tourism operators have been required to offer an all-solve and inclusive plan that combines massive products/services for travel experience [14]. Therefore, a tourist destination must depend on mainstream apps for online travel to produce refined services or they can develop of a new app, which brings difficulties in the research and analysis on destination's information and is unable to provide inclusive services for tourism operators. Firstly, they have to rely on mainstream apps, lacking in flexibility of data collection for customized tourism services; secondly, mainstream apps limit the access to big data in the data analysis of some specific area; thirdly, independently developed apps are faced with high cost of development, popularization, and maintenance. If we can use an existing app, coupled with new technology, the "all-around" services and data collection and analysis of tourist destinations will be of great help to the process of transforming the information of tourist destinations into value.

Nowadays, tourism operators still have not found a proper solution to problems that emerge in data acquisition and analysis of one single tourist destination. This paper focuses on whether we can rely on an existing mobile social media to develop a tool that can not only meet tourist demand on online travel services but also help small- and medium-sized tourism operations provide convenient data analysis for business decisions through a platform of their own. This paper focus on a new useful technological model aimed at improving tourist destination marketing by conducting a case study on the Pingtan comprehensive experimental area in China and proposing an online travel mini program that will focus on consumer behavior and decisions. Moreover, we will show the tourism operators how to use the backstage information provided by this mini program to improve the attractiveness of a tourist destination so as to enhance its competitiveness and consumer satisfaction, as well as to receive guidance for a more precise marketing strategy. This study combines oblique photography, a new type of three-dimensional space measurement, with present social media. Oblique photography technology has been mostly used in homeland security, urban management, disaster assessment, environmental monitoring, real estate, flood risk simulation, aboveground tree biomass estimation, archaeology, engineering construction, and live navigation [15-18]. Such combination realizes information exchange based on the necessity of information and the way of information release, seeking convenient interaction and deep connection between the Internet and tourism and providing reference cases on the sustainable development of tourist destinations. Applying the oblique photography technology to a current app to 
achieve information exchange, combining the necessity of information with the way of information releasing, and seeking for the convenient interaction and the deep connection between Internet and tourism, we present a reference case for other tourism social media, which assists the sustainable development of tourist destinations.

\section{Literature Review}

\subsection{Sustainable and Smart Tourist Destination}

The concept of sustainable development is crucial for tourism both today and in the future [19]. Early in 2005, the United Nations environment program (UNEP) and the World Tourism Organization (WTO) ([20], p. 12) have defined sustainable tourism as "tourism that takes full account of its current and future economic, social and environmental impacts, addressing the needs of visitors, the industry, the environment, and host communities".

Sustainable tourism is derived and developed from the concept of sustainable development and can be defined as a tourism marketing process in which the balance between the high-quality tourist experience of tourists and the high-quality life of local communities is sought and valued [21,22]. In order to make progress, sustainable tourism requires active participation of stakeholders [23]. The sustainable tourism business model is only feasible when marketers, tourists, and local communities cooperate strategically and build up mutually beneficial relationships [24]. With the increasing maturity of mobile technology, online travel service providers provide users with a considerable number of applications which meet users' demands in various aspects through high-quality services and offer tourists better travel experiences. At an international seminar organized by the World Tourism Organization (UNWTO), Buhalis pointed out that information and communication technologies constitute "electronic tools that help company's operations and strategic management, enabling them to manage information, functions, and processes and establish interactive communication to achieve their mission and goals" [25].

Tourists use smart tourism technologies in various stages of making their travel decisions [26]. The findings indicate that smart technologies can enable social media and social networking sites to contribute to sustainable tourism within the smart tourism paradigm [27]. The concept of a smart tourist destination is the result of applying the smart city approach to tourist destinations [28]. The ultimate goal of smart tourist destinations is to improve user travel experience, increase a tourist destinations competitiveness, improve consumer satisfaction, and gain long-term sustainable attention from consumers [29].

In recent years, there have been more individual tourists and people are more inclined to arrange trips according to personal preferences. For example, individuals choose destinations, make travel plans, plan travel routes, and book air tickets and hotels online. The purpose of smart tourism is to make the tour transparent, three-dimensional, and interactive through digitalization, so that tourists can feel and enjoy the charm of a destination. It posts real-time tourism resources, tourism economy, tourism activities, and other information related to tourists to facilitate information needs. Visitors can immediately see and use information, as well as adjust and arrange work/travel plans in a timely manner, which realizes real-time interaction between tourists and the Internet, and makes travel simpler. Smart tourism provides tourists with customized tours and better services and improve tourists' travel experiences, so that tourists can fully experience the benefits of smart tourism during their travels. Smart tourist destinations work together with smart healthcare, smart transportation, and smart public safety to promote the construction and development of smart cities. On the one hand, smart tourism can promote the development of related industries, bring about an increase in urban income, promote the steady growth of the regional economy, and create economic benefits for the city. On the other hand, smart tourism can expand employment, promote the construction of a harmonious society, and enhance the city's popularity and attractiveness, bring social value to the city, and promote the sustainable development of society. 


\subsection{The Choice of Mobile Apps}

In recent years, the emergence of smart tourism and the informatization of tourism have also developed rapidly. Tourism-related websites, social media, and smartphones have been popularized among tourists and the number of them is constantly increasing. According to the 2018 global digital travel sales report, convenient mobile payment options are driving online booking, with global digital travel sales up 10.4\% to \$694 billion in 2018 compared with 2017 [30]. New digital 2020 reports - published in partnership with We Are Social and Hootsuite-show that digital, mobile, and social media have become an indispensable part of everyday life for people all over the world. More than 4.5 billion people use internet in 2020, while social media users are over 3.8 billion; $92 \%$ of the world's internet users are now connected via mobile devices. Mobile apps now account for 10 out of every 11 minutes we spend using mobile devices, with web browsing only responsible for $9 \%$ of our mobile time. China is truly mobile-first, with $95 \%$ of the people accessing the internet via their smartphones [31].

Besides, the growth of tourism investment and tourist numbers has stimulated the surge of tourism app users. Tourists use mobile devices to plan, purchase, and improve their travel experience [32,33]. It is a crucial support for smart tourism destinations that make travel more functional and practical [34]. According to the results of the research survey [35], PC-side traffic in China's online tourism industry stabilized in 2017, with the overall growth rate of online tourism app users reaching a compound growth rate of $32.1 \%$ over the next few years. Therefore, the development of China's online tourism and consumption patterns have changed. At the same time, tourism users have also switched from the PC side to the mobile side, and mobile social media has become a popular platform for users to make travel plans. Past research has shown that travel information circulated and sought in social media had a major impact on tourists' decision-making and behavior [36]. Social media not only allows tourists to search for information about travel destinations but also allows them to make evaluations online (such as reviews, photos, and videos) related to these places $[37,38]$. Social media is now regarded as one of the main sources of big data on tourism and provides huge opportunities for a more decisive process [39]. Seo, Park, and Choi [40] found that the personality and informational characteristics from social media usage had statistically significant effects on electronic word-of-mouth (E-WOM). People who use social media frequently receive unexpected suggestions or recommendations depending on their previous interactions, preferences, and likes [41]. The earlier research conducted by Foux [42] reveals that consumers believe social media is a more reliable information source than the promotion and marketing activities sponsored by enterprises which are the traditional method to popularize commodities and services. Tourist destinations should promote the app as the preferred method for buying online and developing an appropriate strategy [43]. It will help tourists make travel decisions through evaluating the experience of previous tourists. Thus, dialogues with tourists and product promotions should not only be conducted face-to-face at the destination but also online with new technologies and exclusive channels [27]. That means the marketing of the tourist destination not only needs provide inclusive solutions in the app before travel and during travel but also needs maintain the constant connection between tourists and the tourist destination after travel, such as the recommendation and promotion to others by former tourists, a second visit to the destination and sending returned costumers gifts and souvenirs with local features, which requires the tourist destination app be closely and constantly connected with tourists who may receive the information about the tourist destination at any time.

If each tourist destination can develop an app that can provide an inclusive approach to accurate and careful services, the question is that apart from the cost of developing an app and the storage of smartphones, most smartphone users do not like too many apps in their phone. Data show that by the end of October 2018, 4.46 million mobile apps have been monitored in the Chinese market [44]. However, according to the 2018 Q3 report, the total number of apps installed per capita on mobile phones in China is only 50 [45]. The users' preference for less apps increases the difficulty of keeping a tourist destination app in their phone and further increases the difficulty of keeping visitor's 
connected with the tourist destination. On 9 January 2017, the mini program released by WeChat solved this problem.

WeChat is a free application program implemented by China Tencent in 2011, providing the instant messaging service by a smart terminal. It integrates the function of other applications into an all-around service platform including social network communication, mobile payment, e-commercial, and public service, etc. The latest news of Tencent released in March 2018 shows that the usage rate of WeChat among Chinese netizens is up to $94.5 \%$; the number of daily global active users exceeds 1 billion [46]. Moreover, WeChat is based on one-to-one close communication between friends and acquaintances from mobile phone contacts and QQ friends, concentrating on information that shares strong relationship chains. This is an important reason why this study chose WeChat as the research object social media. The function of the mini program in WeChat is a new way to connect users and services, and it can be accessed and shared within WeChat with user experiences [47]. Through the mini program provided by WeChat, various services are offered, including notification, online mall shopping, offline code scanning, and subscription association. Tourists can easily enter and quit official accounts and mini programs, which not only optimize user experience but also is convenient to transfer those mini program users into brand followers. The convenience of the mini program has strengthened the connection between the tourist destination's brand and consumers, creating constant opportunities for the follow-up services. Therefore, on the base of the advantage of massive and highly close-connected users, each WeChat mini program can correspond to one single tourist destination brand, offering potential opportunities to construct a new business ecosystem.

Mini programs are a sort of "light app", because they are connected with dozens of WeChat scene access ports whose number increases, i.e., "used-then-go" and "conveniently to share". Users do not need to install any apps. Instead, they only need to scan or search in WeChat before enjoying the same app functions. Mini programs do not take too much storage or space on mobile phones. After using them, users can find the records stored in "recent used mini program". Even though the mini program was deleted unintentionally, the users can still find it immediately through texts or audios in the search box on the WeChat homepage. It offers an open platform for premium services (Figure 1). Nevertheless, in terms of a user's increasing demands for the richness of content and quality, the mini program, as a light application, is not able to guarantee requirements such as interaction and vision. This paper puts forward the plan of combining oblique photography with mini program to tackle the obstacles above.

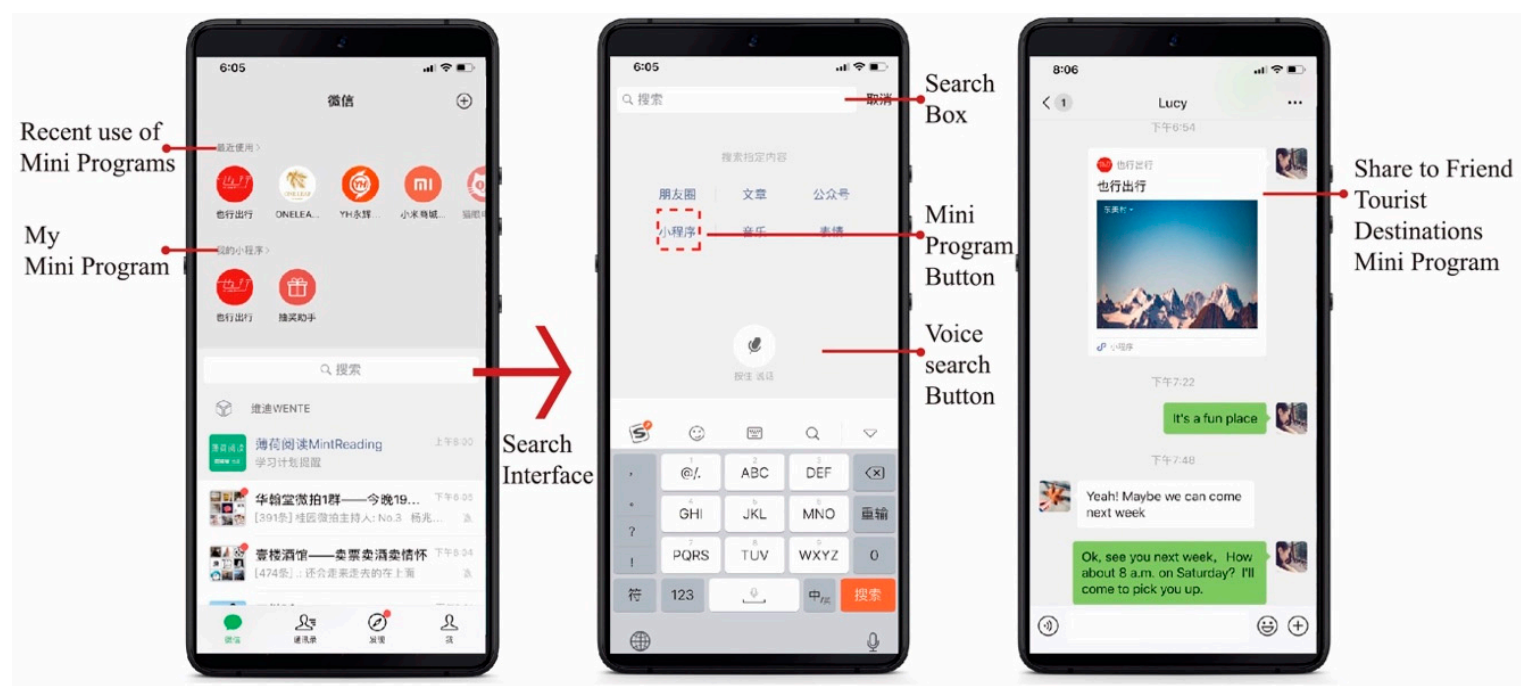

Figure 1. Finding and sharing mini programs in WeChat.

Furthermore, it provides enterprises with publicity, featuring low cost and high transformation rates, providing users with the best carrier for data collection of online travel about tourist destinations. Besides the edges of WeChat, the announced rules in its official design guideline of developing mini 
programs provide a set of instructions for web design and mini programs, which provides useful resources for developers and proposes visual standards on interface design including font, font color, button, and chart [47], bringing great convenience to developers. Meanwhile, compared with various apps, the integration of the user interface (UI) of WeChat mini programs and operation procedures improves user's usability.

\subsection{The Oblique Photography Technology in Tourism Applications}

The oblique photography technology can simultaneously collect target images from five different angles including a vertical angle and four slope angles to capture the detailed and high definition images of a building's texture from the top and sides. It not only can reflect the real condition of object surface and accurately acquire the texture information of images but also has advanced techniques such as locating, integrating, and modeling [48]. The oblique photography mainly relies on unmanned aerial vehicle (UAV) aerial image for high accuracy and three-dimensional quality, which has the features of flexibility, efficiency, low cost, multiple angles, vast scale, high definition, and easy online publishing due to a small amount of data. Much of the previous oblique photography research concentrated on areas such as emergency command, homeland security, city management, disaster evaluation, environment monitor, real estate, flood risk simulation, aboveground tree biomass estimation, archeology, engineering construction, and real view navigation [15-18]. Though vast applied researches have been conducted on oblique photography technology and its advantages shown in other fields have been discussed, few papers concentrate on the oblique photography in tourism, especially from the perspective of analyzing it with the assistance of data and social media through which the massive data produced by the tourist travel terminal can efficiently bring value to tourist destinations $[15-18,49,50]$. Big data generated by users, as well as real-time analysis and data synchronization, have become the main driving forces of the value creation process of smart destinations [29]. On the basis of satisfying consumers' demands and bringing the utmost benefits for operators with deep-in researches and objective analysis, we find oblique photography combined with the tourism industry can be transferred into commercial value, which can be regarded as an output port.

Proper management, repair, and maintenance of tourism resources have an extremely important role in tourism development and are key to sustainable development of tourism resources, which can facilitate tourists' visit so as to improve their satisfaction and travel experience, Moreover, they show great significance in promoting tourism consumption, social development, and economic growth. In the process of displaying tourist destinations in the past, most operators collected various scenes and features of the destination and then selected representative scenes with video explanations, celebrity interviews, and other materials. However, such approaches do not fully display the original features of the land. With the help of oblique photography measurement technology, this problem can be effectively solved. At the same time, three-dimensional images produced by oblique photography show significant advantages in the development and management of tourism destinations, which offers the perspective of planners and tourists so that users can fully observe different stages during the planning and construction of a tourist destination. In addition, oblique photography can comprehensively measure three-dimensional information, such as the original features and historical buildings, providing accurate and clear data for the subsequent maintenance and repair of the destination.

In summary, the application of oblique photography technology in scenic spots will improve the entertainment and enrichment of scenic spots, and the final three-dimensional (3D) geographic information frame will provide a base for the subsequent construction and planning of the tourism destinations, especially on scientific protection, reasonable exploitation, effective operation, scientific management, and planned development and introduction to new amusement programs, which will avoid mistakes caused by the lack of geographic information. This research puts forward that oblique photography can be applied in tourism, and with some software including Inpho, Pix4Dmapper and Street Factory, the real scene 3D modeling of the tourist destination will be available, which 
demonstrates the surrounding, the outside looking, location, height of buildings in the tourist destination, and provides an effective method of basic information acquisition for tourist destinations. For the use of multiple angle's photography measurements and the outcome of large-scale mapping, users are provided with enriched geographic information and details about the surroundings of their destinations, as well as friendlier user experiences and local services. For data usage, a data vectorization technique, ArcGIS (Geographic Information System) is used to decode and interpret scenic spots, streets, buildings, and sceneries. Through the advanced location technique, the exact geography, humanity, and marketing information can be embedded, and the 3D scene map and route design will be shown, expanding the application field's scenic spots.

Against the above background, the innovation of this study is to propose that it is feasible to apply oblique photography to mobile social media and combine it with tourism. Oblique photography has a dependent system that bridges the cloud server, which shares the commonality of the mobile set. Thus, social media only needs to build and adjust to the corresponding webpage to present the real 3D map of the destination, which builds a deep interaction between tourist destinations and consumers from the mobile network terminal, realizing the functions of visitors punching the clock in the scenic spots online and long-distance visits of scenic spots. Before traveling, tourists can have a general understanding of destinations through mini-programs and quickly make travel decisions and reasonable arrangements for routes. Using mini programs during travel helps people notice places that are unintentionally ignored at most tourist destinations, providing real-time local public service needs and route recommendations. After traveling, tourists can purchase souvenirs related to travel destinations in the mini program mall and comment on the destination. Some will recommend it to friends, thereby transforming users into word-of-mouth advertisers and improve the popularity of the tourist destination. Therefore, consumers will be steadily connected with their tourist destination and business links will be triggered. Meanwhile, it will enrich the experience of the tourist destination and exploit a territory to the ways of data capture and information flow for tourism. In the future, researchers will further develop oblique photography and mobile technology, aiming to provide tourists with higher quality services, promote the planning of tourist destinations, and trigger further progress in tourism, which supports the urban construction and economic growth to achieve the goal of sustainable development of tourism.

\section{Materials and Methods}

In order to find out whether social media combined with oblique photography smart technology can contribute to the sustainable tourism industry in the smart tourism paradigm, this study launches a project where oblique photography technology and social media are combined to develop a mini program, which is a one-stop tool for making travel plans that meets relevant stakeholder demands. These stakeholders include tourists, tourist destination operators, suppliers, and local residents. Using the Tokai Wonderland attractions in the Pingtan comprehensive experimental area as a sample, this study uses empirical research methods to develop a light application that combines social media with oblique photography to improve online travel services and demonstrates the thinking process of mini program development. The Pingtan comprehensive experimental area is located in the east of Fujian Province; the Tokai Wonderland attractions are on the east side by the sea, covering an area of 7.5 square kilometers. Due to its geological structure and long-term seawater and aeolian sand erosion, it has been turned into a magnificent and mysterious sea eroded landform. Furhter, it was nominated as a Haitan National Scenic Area on 10 January 1994 [51]. In this study, large-scale modeling work has been done in the Tokai Wonderland attractions and two nearby villages. By oblique photography technology, the scanning speed is accelerated and the cost of artificial modeling is reduced. The team only spent one day on field scanning and five days on 3D data reconstruction on the computer. In total, we spent six days restoring complex three-dimensional scenes of the Tokai Wonderland. Finally, the corresponding webpage is constructed and adjusted, and the real 3D map of Tokai Wonderland is presented on a WeChat mini program service (Figure 2). 

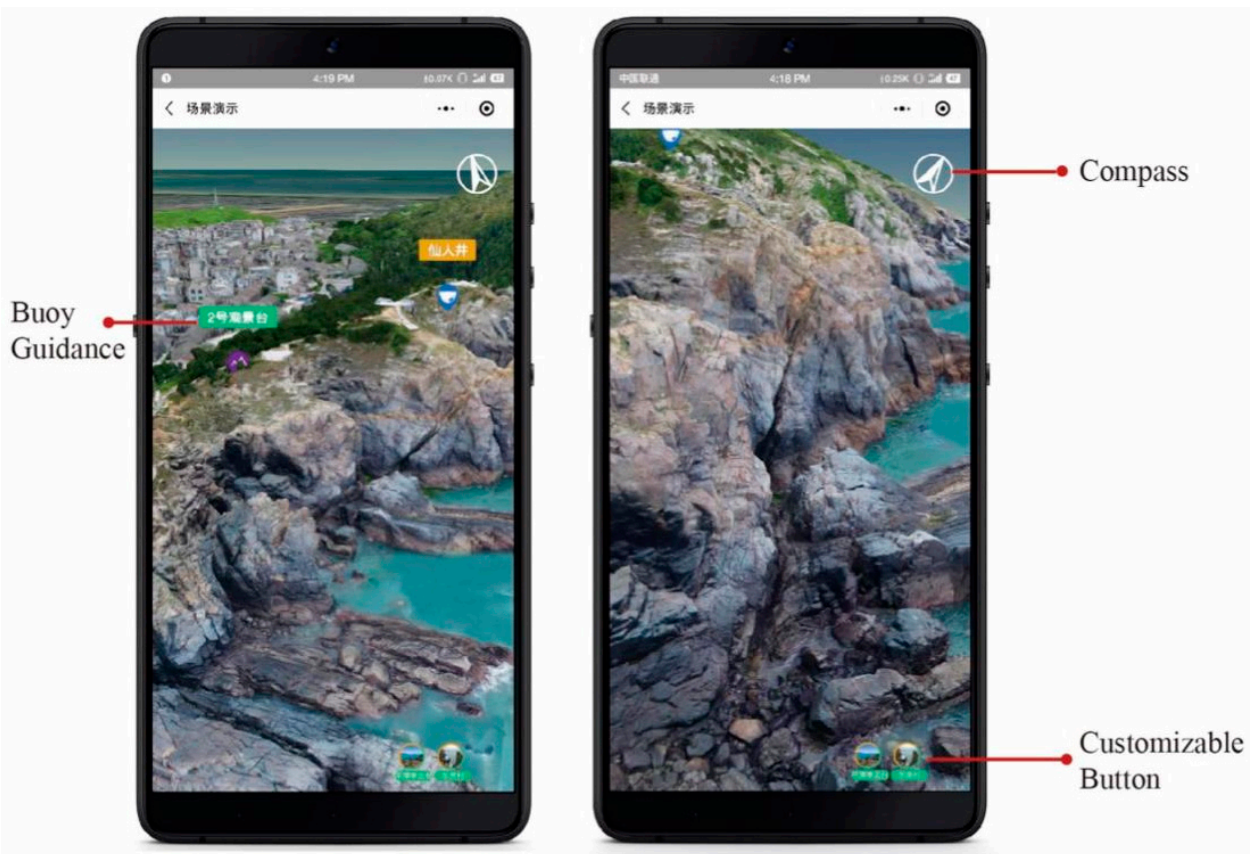

Figure 2. In a WeChat mini program, the three-dimensional (3D) reality restoration of Tokai Wonderland attractions are displayed based on oblique photography.

Schiffman, Kanuk, and Wisenblit [52] defined consumer behavior as the behaviors that appear in the period when a consumer searches, purchases, uses, evaluates, and deals with services and products provided by operators who believe that customers expect there products and services. In the past, consumers did not actively seek information from the market but rathee received help from exterior agents who will filtered information, selected products, gave advice, and even represented consumers to make decisions [53]. Based on Solomon's research, Stone [54] confirms that travel agents are an essential part of travel decision-making. Nevertheless, the wide use of mobile devices, the fluency and smoothness of network connection, the improvement of travel apps, and the convenience of mobile payment have stimulated the growth of social network services. Social media as an information source for travelers plays an important role. Apps are now major assets with regard to booking tickets and hotels, as well as searching for travel tips. In the tourism industry, social media is a unique marketing and communication tool for marketing personnel, because they can directly interact with tourists to affect decision-making $[55,56]$. Meanwhile, social media tremendously affects how customers search and share information, even after they have decided where they are going. Thus, when developing the mini program, we should include the function of a travel agent's decision-making throughout the entire process. Figures 3 and 4 show the mind maps of the process of developing this new mini program.

Figure 3 shows that consumers at the first stage of "need recognition" evoke the demand for traveling. The second stage is "information search", where users search the conditions and information of their desired destination on the mini program to make an "alternative evaluation". The third stage is "choice decision". Through the functions of the mini program, users decide whether to visit the tourist destination and then book tickets and accommodations. "During Trip" is the fourth stage, wherein the mini program can provide instant information and assist interaction at the tourist destination. The fifth stage is the "post-trip evaluation", which includes users using the mini program to share and evaluate the trip and purchase local products. The mini program penetrates the entire travel service circle and plays an important role in decision-making. What is more, with the function of electronic word of mouth (e-WOM), it completes a closed loop in the travel decision-making process. The role of e-WOM is similar to advertisements that cause potential tourists to achieve a virtuous cycle of tourism economic growth for tourism purposes. 


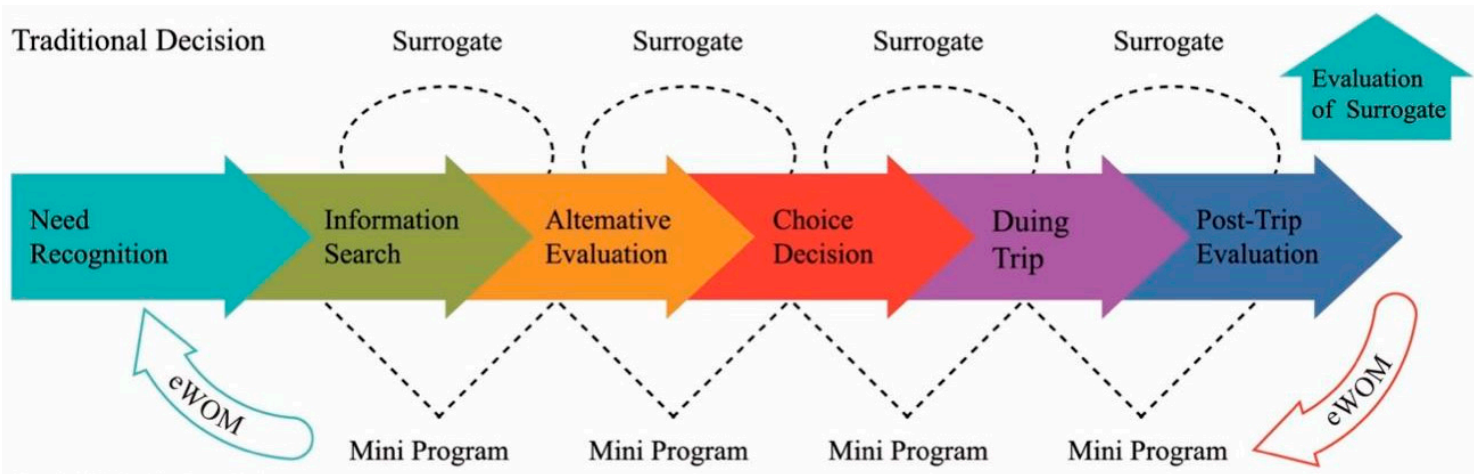

Social Media Decision

Figure 3. The simplified model of mini programs replacing surrogates in the decision-making process (Solomon, 1986). E-WOM: electronic word of mouth.

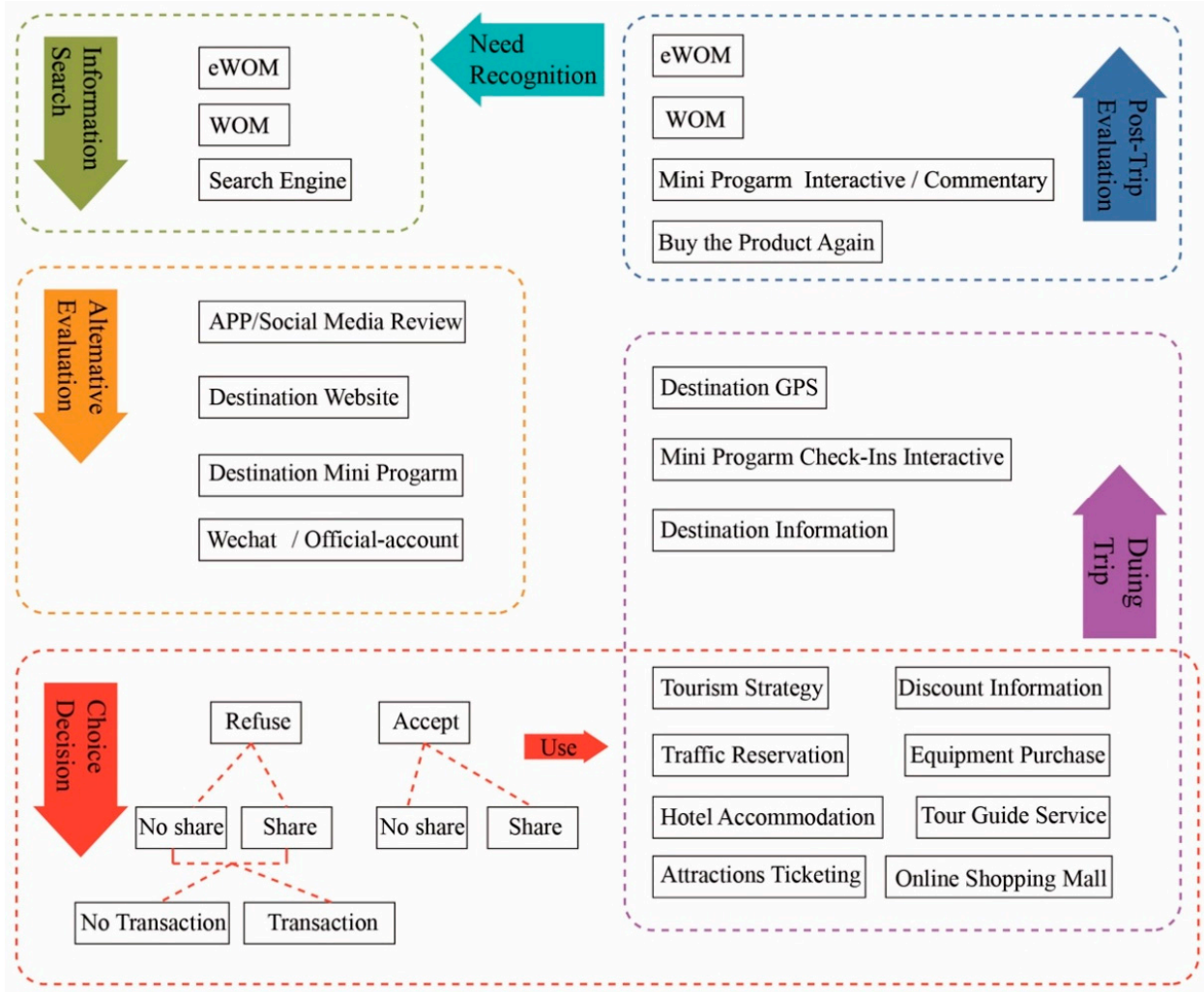

Figure 4. The mind map of a consumer when using the mini program.

Previous research has discerned that some tourists decide their travel destination according to comments written by those who have already visited [57-59]. Naturally, a good travel experience will produce word of mouth that will create a tremendous influence via the spread of social media and travel review websites [60]. According to Penguin Intelligence, tourist users are used to preparing travel schedules on travel apps in advance and the one-stop service is preferred by users in which travel tips, accommodation reservation, and transportation reservation are the most popular, followed by equipment purchase, scenic spot ticket booking, discount information, and pick up service [61]. Those who are content with these services are most likely to not only visit again but become faithful customers and recommend the corresponding products to others. This is incredibly important for face-to-face interaction during the trip and comments after-sales service can influence the decisions of potential customers in the earlier service stage [62,63].

Clatworthy [64] defines a service supplier interacting with clients from various aspects. At the a tourist destination, products are mainly service and include various contact points before, during, 
and after travel. Trying to satisfy clients' expectations is vital to improve their satisfaction, which needs to continuously be measured [65]. Therefore, we list all possible interactions and contact points between tourists/potential tourists and the mini program (Figure 3). This can be referred to as a basis for the design of function modules in mini programs.

In Figure 4, it is clear that, after the "demand recognition" stage before the trip, potential tourists during the "information search" are most likely to know the tourist destination through e-WOM, recommendations from relatives, or mini program searches. During "alternative evaluation", tourists resort to travel apps, social media reviews, websites, mini programs, WeChat, or its subscriptions to decide whether to go. Now, however, potential tourists can experience reality demonstrations through the $3 \mathrm{D}$ view provided by oblique photography technology. At the stage of "choice decision", tourists may decide to set off or instantly recommend the destination to others. Then, they are likely to prepare for the trip using the mini program. Such preparations include searching for travel tips, reserving hotels, and learning traffic information. Those who decide not to go will probably share the mini program to others. What is superior to the traditional ways of promotion is that consumers may use the mini program's online shopping mall and WeChat payment to buy local products online, which creates a new sales method for the destination's specialties and an opportunity for the destination to advertise itself. For the "during the trip" stage, tourists can use the mini program to search for information and acquire travel tips, which, unlike the traditional Global Position System (GPS), enables tourists to experience a 3D view and punch the clock when they arrive at the spot marked in the mini program. This promotes the close interaction between tourists and the tourist destination. During the "post-trip evaluation" stage, tourists may share the mini program to others, make comments in the mini program, and buy local products again through the mini program's online shopping mall. These functions invisibly influence customer's demand recognition and further contribute to a closed loop of consumer decisions.

Figures 5 and 6 are demonstrations of the Tokai Wonderland attractions of the Pingtan comprehensive experimental area in Wechat. What we need to do is to find the contact points in the choice decision process and figure out how to optimize the functional module of the destination to offer a better online experience, raise consumer satisfaction, win more positive e-WOMs, and achieve sustainable development of the destination.

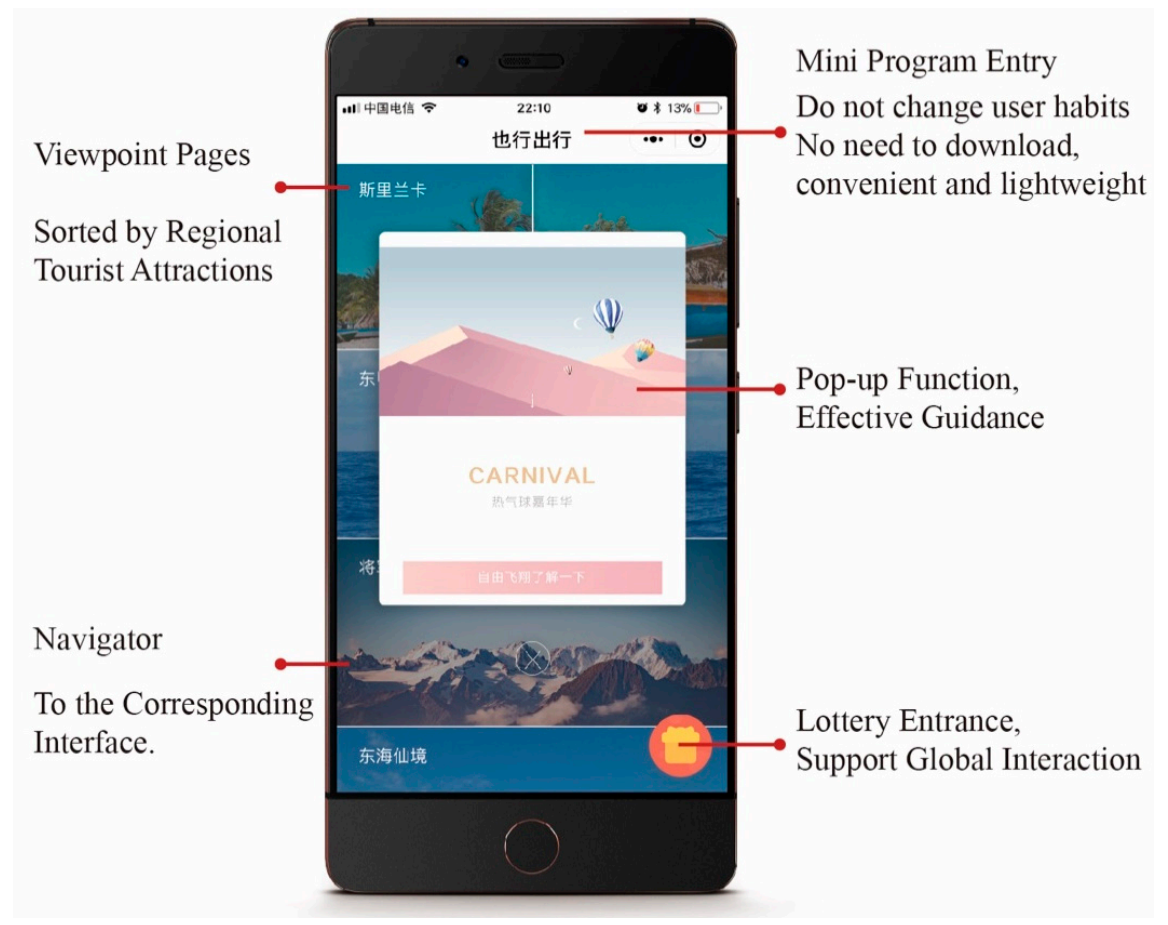

Figure 5. The homepage of tourism service in the WeChat mini program. 


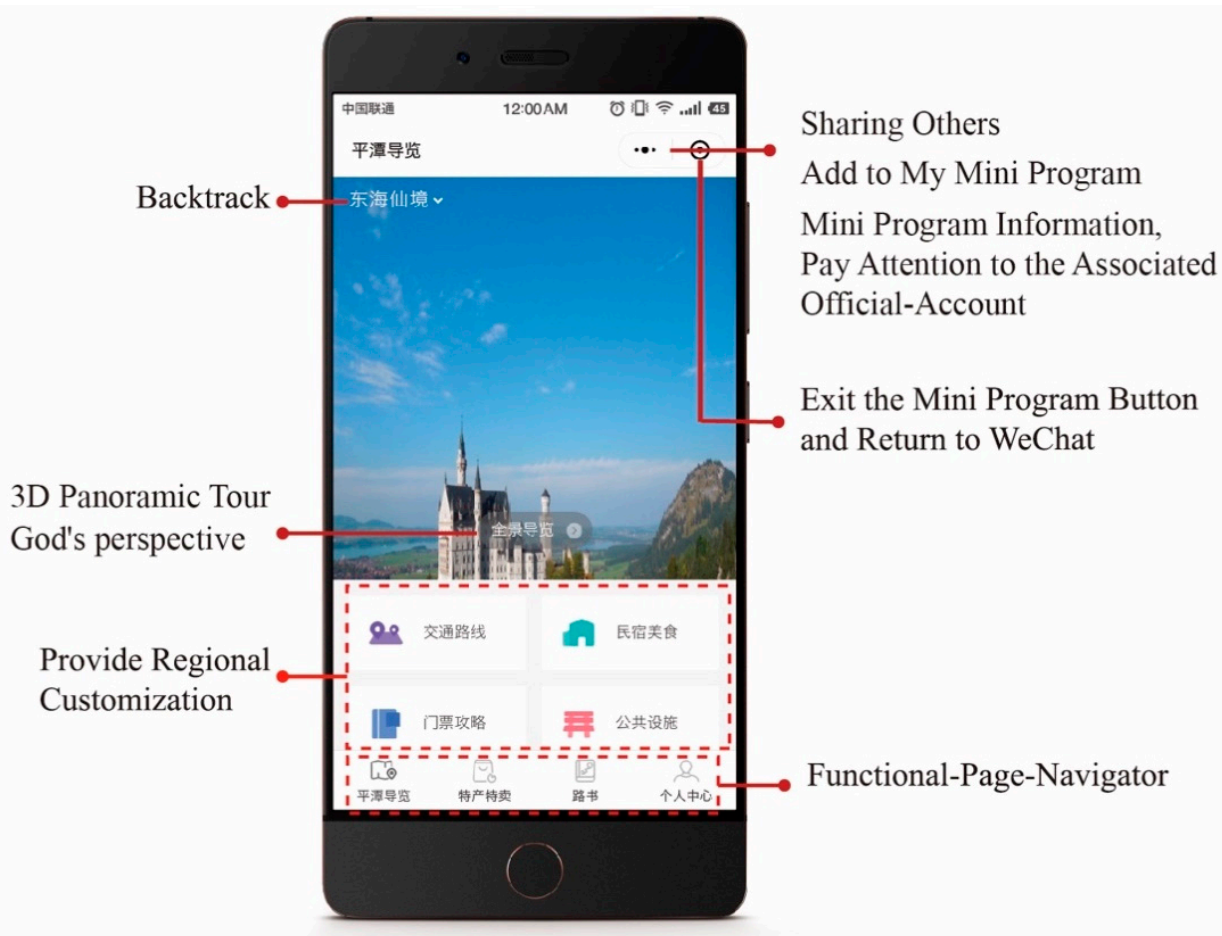

Figure 6. The sub page's column navigation of the Tokai Wonderland attractions in the WeChat mini program.

Figure 7 demonstrates 3D images of a tourist destination, so that non-WeChat users and domestic and foreign tourists who prefer using a PC can access the web through a link. Since this study mainly discusses the innovative use of combining oblique photography technology with social media on mobile devices, the computer version will not be discussed in detail.
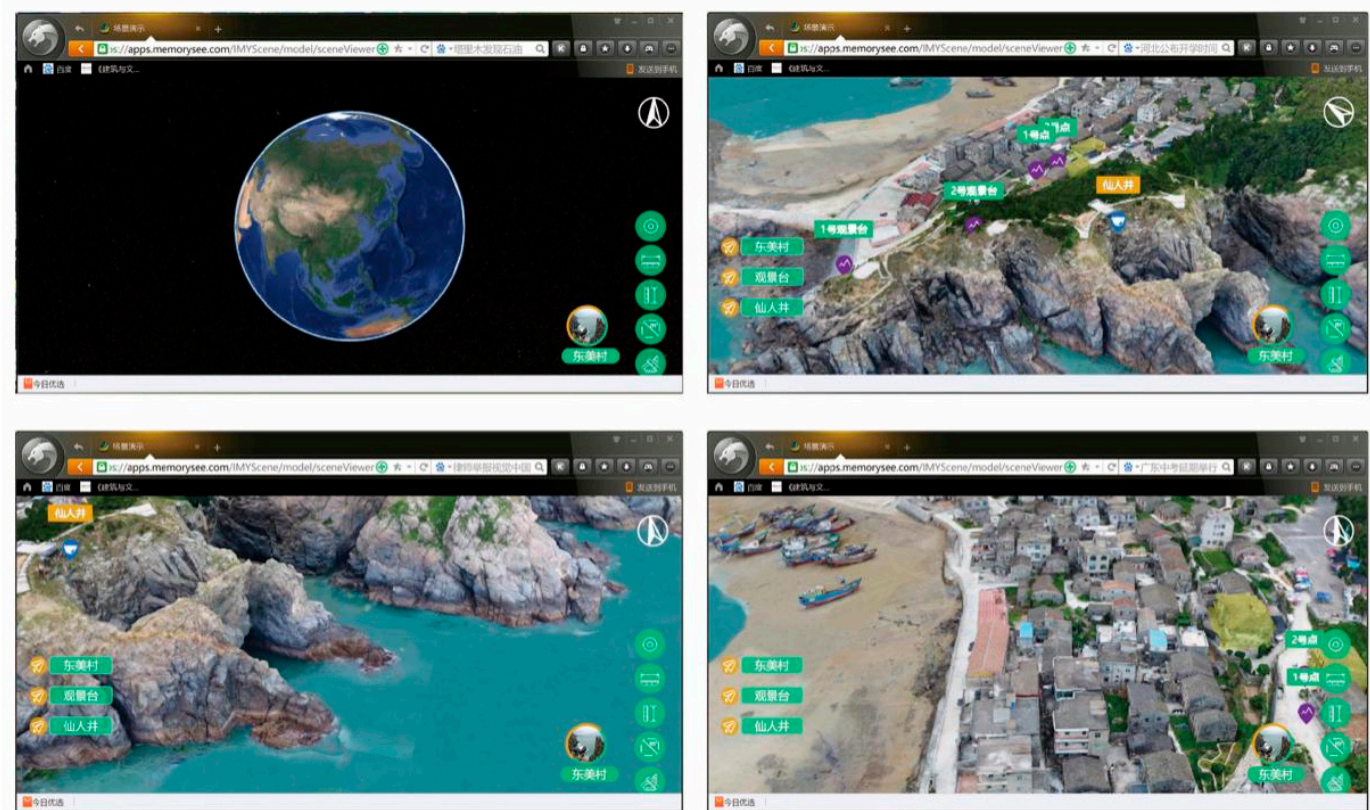

Figure 7. The computer version of 3D images of the Tokai Wonderland attractions in the Pingtan comprehensive experimental area. 


\section{Results and Discussion}

This study combines social media applications with oblique photography technology on mobile devices and realizes the use of three-dimensional scenes of travel destinations in online travel applications. The travel application of social media combined with oblique photography technology allows tourists to interact more actively with destinations and collect more targeted information, which plays a very important role in marketing tourist destinations. Various stakeholders (e.g., communities, government agencies, suppliers, tourist destination managers, non-profit organizations, tourists, etc.) will benefit from the data collected on this mini program. In 2000, Gordon Philips [66] proposed that the concept of smart tourism is a comprehensive, long-term, and sustainable method to plan, develop, operate, and market products and tourism businesses. In fact, the big data generated by user-generated content and the real-time analysis and synchronization of these data have become the driving force of the smart destination value creation process [29,34]. They can analyze tourism profiles with more details, including the sociodemographic profiles and users' preferences, feelings, and attitudes. These data are useful for creating tourism services that better meet the demands of tourists [8]. In addition, factual information about a tourist destination retained by oblique photography brings stable resources, culture, environment, and civic life quality, including life safety and tourist property protection. Through the Internet, data collection, feedback, and decision-making optimization, the entire system of stakeholders operates jointly, bringing benefits to the sustainable development of tourist destinations. The following parts will focus on the benefits of these data for tourists, tourist destination marketers/planners, and government agencies.

\subsection{For Tourists}

Compared with the application's interface adopting traditional panoramic photography, oblique photographs show the real scene in an overall view on one page and thus no secondary page is needed. Tourists are able to zoom in and out in the demonstration page. With markers and page modules, it distinctly shows the regional service distribution. With such functions, tourists can easily reserve services from the tourist destination and shop online at any time. These functions can be presented on one page, meaning it contains overall information on the destination. Oblique photography enables users to observe the sites from multiple angles. The overall view directly represents the real situations of the tourist destination, because this technique can capture the map of dozens of buildings, shaping it into a terrain model that could generate a sight shock. In the field of tourism, tourists do not merely have relations with the scenic spot but are connected with the place out of their basic demands on traveling. In the 3D vision, apart from the scenic spots, users can also have an overview of surrounding areas because the mini program clearly shows the location of hotels, nearby scenic spots, ATMs, medical care centers, and public facilities.

The 3D model based on oblique photography can add many dimensions to information. Not only has it replaced the traditional scenic spot map but it instantly locates tourists and recommends routes according to live scenes. In addition, different types of tourists, such as free travel, group tourists, elderly tourists, or parent-child tourists, can quickly and accurately decide the travel route from the $3 \mathrm{D}$ reality images. In route recommendation, the interaction button on the main page can be motivated, which is a surprise entrance to many interactive activities, allowing users to to know activities and achieve original goals orientationally. Furthermore, we are able to construct different modular designs for different tourist destinations and choose different marketing tools and ways of interacting. Mini programs provide services such as navigation, tour guides, shopping guide sharing, public service, and real-time travel route recommendation, which appropriately designs the travel routes and makes travel plans for tourists in advance to save their time so that tourists can quickly get familiar with the surrounding. Based on the mini program's online payment function, it offers one-stop and inclusive services for tourists, thus improving their satisfaction degree, promoting tourism consumption, and stimulating tourism economic growth. 


\subsection{For Tourist Destination Managers/Planners}

For tourist destination managers, the biggest advantage of mini programs from an information perspective is that the data are preserved by operators. In order to enable mini program developers and operators to easily view mini program information, many data analysis platforms have emerged, especially for mini program data analysis (Table 1). The tools of these data analysis platforms include the following analytical layers in order to better understand users and optimize the mini program to contribute to the transformation of data into value:

1. Application analysis contains live data, historical trend, web page analysis, etc., from which we can know how long users stay on the interface, user preferences, and the last web page the user visited. According to the statistics of a users' page staying time, the fit points between users' preference and the importance of popularization will be found to adjust the ways of information, releasing management concepts so as to ensure a second visit and leave a chance to collect more information from these users next time.

2. Environment analysis is the analysis of regions, terminals, network, mobile types, etc., which helps operators understand the mini program's operating environment.

3. User exploration analysis concludes user tracking, user role, new and regular users, users' retention rate, user activation, user turnover, and the inverse flow rate of users, which can be used by operators to target the objective user group. According to the distribution of user's browsing time, it targets the golden time to update the latest information of destination activities for the faithful clients and vast customer groups so as to reach a high information-receiving rate. According to the user analytics, it can ensure major users visit the tourist destination. Therefore, we can adjust the scene in the mini program according to their age, gender, and education background to improve the ways of meeting user demands and strengthen the relationship between the mini program and its users.

4. User behavior analysis includes the list of events, event details, funnel plot analysis, etc., which can precisely show the concrete reason for user loss. By analyzing the number of users in every link, we can find out the part that leads to user loss and warn the operators to take timely actions to deal with abnormal statistics.

5. Usage analysis covers the analysis of sharing, pull-to-refresh, bottom reaching, time of using period, etc., which can quickly give feedback so as to adjust unreasonable page modules and even the way of displaying information. Based on most users' browsing habits, it helps adjust the contents of the subordinate page so that the sub-subordinate page can effectively lead users to interfaces which may trigger their desire to visit or to shop.

6. Business analysis of e-commerce consists of transaction analysis, repurchase rate analysis, etc., which can analyze the acceptability of new products so as to produce more popular ones, improve those that are not so popular, or upgrade services.

7. Source analysis consists of channel analysis or data sources. The mini program has many entrances and each entrance has a corresponding scene ID number. Thus, the operators can decide the ratio of different ads according to the statistics from different scene ID number.

8. The heat map shows the number of page views of each interface and the preference of clicks, from which we can immediately find out whether the current frame of interfaces is appropriate or whether the interfaces are too compact. If so, we can timely add the missing information to increase user's involvement and target conversion rate.

9. Mini program user analysis can be a reference for our media, the WeChat subscriptions about the tourist destination is connected with the mini program. It can combine various media terminals to access efficient information to upgrade the modes of business operation and provide proper discounts for sponsored content. The heat map of a tourist's preference can help design customer-oriented activities of the tourist destination. 
10. According to the data of past visits to the mini program, operators can effectively predict the number of tourists in the scenic spots of the tourist destination, improve the quality of management, arrange staff, facilities, and performances, improving the configuration of relevant scenic resources.

11. The data collection from tourist evaluation, complaints, and suggestions can strengthen the effective contact and interaction between tourists and tourist destination operators who are able to collect real-time feedback to improve the level of customized services and make more appropriate plans for tourist destinations.

Table 1. Analysis platforms for mini programs.

\begin{tabular}{|c|c|}
\hline Analysis Tools for Mini Programs & Functions \\
\hline $\begin{array}{l}\text { Tencent mobile analysis } \\
\text { WeChat mini program's analytics }\end{array}$ & $\begin{array}{l}\text { Application analysis, environment analysis, user } \\
\text { analysis, custom events, source analysis, usage } \\
\text { analysis, etc. }\end{array}$ \\
\hline Baidu analytics & $\begin{array}{l}\text { Custom analysis, user analysis, using behavior, } \\
\text { thermodynamic diagram, channel analysis, start-up } \\
\text { source, retention analysis, conversion analysis, etc. }\end{array}$ \\
\hline TalkingData & $\begin{array}{c}\text { Data overview, user exploration, user's behavior } \\
\text { analysis, e-commerce business analysis, statistics } \\
\text { exploration, etc. }\end{array}$ \\
\hline ALaDing mini program analytic tool & $\begin{array}{l}\text { Data overview, scene analysis, QR code channel, AD } \\
\text { monitoring, sharing analysis, page analysis, events } \\
\text { and conversion analysis, user sorting, personas, etc. }\end{array}$ \\
\hline WeChat public platform & $\begin{array}{l}\text { Overview, real-time statistics, visiting analysis, source } \\
\text { analysis, user analysis, custom analysis }\end{array}$ \\
\hline $\begin{array}{l}\text { Mini program data analysis helper (official mini } \\
\text { program tools) }\end{array}$ & $\begin{array}{l}\text { Data overview, visiting basic analysis, real-time } \\
\text { analysis and personas, etc. }\end{array}$ \\
\hline Hot app mini program analytics & $\begin{array}{c}\text { Statistical profile, QR scan statistics, user analysis, } \\
\text { sharing analytics, events statistics, event } \\
\text { management, user's feedback, etc. }\end{array}$ \\
\hline Sensors data & $\begin{array}{l}\text { Event analysis, funnel plot analysis, retention } \\
\text { analysis, distribution analysis, user paths, heat map } \\
\text { of web page, attributive analysis of users, etc. }\end{array}$ \\
\hline Growing IO statistical analysis of mini program & $\begin{array}{l}\text { The visible board of core products, product purchase } \\
\text { conversion; the visible board of core indicators in } \\
\text { investment, user attribute, the core indicators of } \\
\text { market and customer acquisition, the heat map of } \\
\text { operation analysis visible board, conversion rate, etc. }\end{array}$ \\
\hline
\end{tabular}

With the development of the Internet, the efficient acquisition of user information has become the most valuable market resource. Operators do not need to rely on a tycoon's app or invest in the development of a new app. Instead, operators can collect data precisely and transfer valuable information so as to acquire the orientations of operation, development, and optimization of comprehensive and inclusive services. Such combination of oblique photography and mini program's big data acquisition saves the operators a large amount of cost, for they do not need to develop a new app or invest in its maintenance; the mini program provides the operators with user statistics. In addition, the results presented by the mini program's background data can effectively improve the management level of tourist destination operators, promote the innovative development of tourism products and services, and provide suggestions to help planners make long-term plans to balance the interests among various stakeholders, promoting the sustainable development of tourist destinations. 


\subsection{For Government Agencies}

Based on the application of combining oblique photography technology with WeChat mini programs, the 3D geographic information of the restored tourist destination can provide a geographic basis for subsequent construction, planning, protection, development, and management. The mini program's information sharing platform can help government agencies find out problems more easily through smart office, smart supervision, smart service, and smart decision-making, improving the management level, coordination, and service ability of various functional departments for tourist destinations. Through the real-time positioning of tourists in tourist destinations and the heat map feedback on travel routes and public service demands, it can be seen that:

1. It helps the government to play the guiding role in the early stage of tourism development and construction, making appropriate plans and designs for the tourism resources.

2. It helps government agencies carry out comprehensive diagnoses and orderly management of construction through the organization and management mechanism, so that tourism public services including life services, hospitals, transportation, tourist centers, and other resources.

3. It helps government agencies play a leading role in terms of capital and acquiring a global perspective on the capital investment through tourism popularization.

4. It helps government agencies quickly respond to the structural adjustment of the local tourism industry, prompting it to further expand, develop, transform, and upgrade.

5. It helps government agencies realize smart scheduling, improve the efficiency of various management activities of tourist destinations, and promote healthy and sustainable development for the tourism industry.

Currently, the developing function of the mini program is being improved. The operators of each mini program can independently develop and add new functions according to their own demands. Therefore, through the Internet, the operators can resort to highly efficient media platform to take full advantage of the interaction function of the mini program, for the tourism industry is featured with sharing information, and is thus more likely to discover new ways to stimulate consumption and increase interest growth rate. Combination with oblique photography is a positive attempt for interactive conversion.

\section{Conclusions and Limitations}

Social media is an increasingly important partner to the tourism industry. Making full use of mini programs and embedding oblique photography technology has become a new element and new selling point for the tourism industry. This study analyzes and regards oblique photography as an important technical method of smart tourism. A newly emerged technology of 3D space measurement is characterized by its flexibility, low cost, multiple angles, large range, and high definition, providing efficient technical means for basic data acquisition of tourist destinations without costing manpower, material resources, and financial resources for repeated measurements. Using oblique photography technology to obtain 2D and 3D data at once reflects the secondary, location, height, and other data of the tourist destination. The 3D model enhances the vividness and provides reliable basic data for the coordinated development of proper protection, appropriate development, effective management, and proper management of tourist destinations.

There is no doubt that the combination of oblique photography and mini program provides comprehensive service and more convenience for regional tourism. Not only does it interact with tourists perfectly in each service link but it provides a way to access statistical information and reverse information, thus connecting operators with consumers. In this study, the unresolved problems in the literature review are fixed. The application of oblique photography technology is moved from the PC to mobile. This paper clarifies the contribution of oblique photography to online travel services, making up for the vacancy of the real-time interactive experience of tourists in other small-scale tourism applications. Taking the Tohai Wonderland attractions in the Pingtan comprehensive experimental 
area as an example according to the mind map of tourists using mini programs, this paper conducts a case study on the application of oblique photography to a mini program. The background data analysis of the mini program can guide the development and operation of a tourist destination business, providing provide operators with the value conversion of a user profile analysis. This case provides a reference for other social media tycoons (i.e., Facebook, Instagram, LinkedIn, Line, Twitter, etc.) and apps for online travel such as Ctrip and Booking, for it is based on a large number of users. With the emerging technology and oblique photography, there is a new online interaction between users and tourist destinations.

However, oblique photography has its limitations. Successful and smooth high-definition image display can be affected by a network's bandwidth. With the popularization of 5G (the 5th generation wireless systems), this problem will be solved soon. This study also conducts an in-depth analysis of relative stakeholders such as tourists, tourist destination managers, and government agencies. In future research, we will apply case demonstrations to the practical use of specific tourist destinations, collect real statistics to verify the effectiveness and feasibility of such combinations, and optimize the tool set. We will demonstrate and explain how to analyze the data in real conditions and reshape it as the target big data by trying to use the research results as a reference for stakeholders so as to fully promote the sustainable development of tourism.

Author Contributions: This research conceptualization by M.L. and F.-Y.L.; methodology by F.L.; investigation by M.L. and H.Z.; resources by H.Z.; writing—original draft preparation by M.L.; writing-review and editing by F.-Y.L., M.L. and H.Z.; visualization by M.L. All authors have read and agreed to the published version of the manuscript.

Funding: This research received no external funding.

Conflicts of Interest: The authors declare no conflict of interest.

\section{References}

1. Serrano, L.; Sianes, A.; Ariza-Montes, A. Using Bibliometric Methods to Shed Light on the Concept of Sustainable Tourism. Sustainability 2019, 11, 6964. [CrossRef]

2. Nations, U. Transforming Our World: The 2030 Agenda for Sustainable Development; United Nations General Assembly: New York, NY, USA, 2015.

3. China Tourism Academy. Basic Situation of Tourism Market in 2019. Available online: http://www.ctaweb. org/html/2020-3/2020-3-10-16-48-64712.html (accessed on 8 April 2020).

4. Moral, M.M.; Alles, M.T.F.; Franco, M.J.S. Attitudes of rural accommodation managers towards the development of sustainable tourism. Cuad. Tur. 2018, 41, 707-711.

5. Cuesta-Valiño, P.; Bolifa, F.; Núñez-Barriopedro, E. Sustainable, Smart and Muslim-Friendly Tourist Destinations. Sustainability 2020, 12, 1778. [CrossRef]

6. Jafari, J. The scientification of tourism. In Hosts and Guests Revisited: Tourism Issues of the 21st Century; Smith, V., Brent, M., Eds.; Cognizant Communication Corporation: New York, NY, USA, 2001; pp. 28-41.

7. Hjalager, A.M.; Nordin, S. User-driven innovation in tourism-A review of methodologies. J. Qual. Assur. Hosp. Tour. 2011, 12, 289-315. [CrossRef]

8. Del Chiappa, G.; Baggio, R. Knowledge transfer in smart tourism destinations: Analyzing the effects of a network structure. J. Destin. Mark. Manag. 2015, 4, 145-150. [CrossRef]

9. Encalada, L.; Boavida-Portugal, I.; Cardoso Ferreira, C.; Rocha, J. Identifying Tourist Places of Interest Based on Digital Imprints: Towards a Sustainable Smart City. Sustainability 2017, 9, 2317. [CrossRef]

10. Bustamante, A.; Sebastia, L.; Onaindia, E. Can Tourist Attractions Boost Other Activities Around? A Data Analysis through Social Networks. Sensors 2019, 19, 2612. [CrossRef] [PubMed]

11. Malik, K. Optimal Travel Route Recommendation Mechanism Based on Neural Networks and Particle Swarm Optimization for Efficient Tourism Using Tourist Vehicular Data. Sustainability 2019, 11, 3357. [CrossRef] 
12. Li, Q.; Li, S.; Zhang, S.; Hu, J.; Hu, J. A Review of Text Corpus-Based Tourism Big Data Mining. Appl. Sci. 2019, 9, 3300. [CrossRef]

13. Ting, L.; Jian, H.X.; Crowe-Delaney, L. Tourism Information Diffusion through SNSs: A Theoretical Investigation. Sustainability 2020, 12, 1731.

14. Buhalis, D.; Law, R. Progress in information technology and tourism management: 20 years on and 10 years after the Internet-The state of eTourism research. Tour. Manag. 2008, 29, 609-623. [CrossRef]

15. Yang, G.D.; Wang, M.S. The Tilt Photographic Measuration Technique and Expectation. Geomat. Spat. Inf. Technol. 2016, 39, 13-18.

16. Wu, Y.; Peng, F.; Peng, Y.; Kong, X.; Liang, H.; Li, Q. Dynamic 3D Simulation of Flood Risk Based on the Integration of Spatio-Temporal GIS and Hydrodynamic Models. ISPRS Int. J. Geo-Inf. 2019, 8, 520. [CrossRef]

17. Lin, J.; Wang, M.; Ma, M.; Lin, Y. Aboveground Tree Biomass Estimation of Sparse Subalpine Coniferous Forest with UAV Oblique Photography. Remote Sens. 2018, 10, 1849. [CrossRef]

18. Verhoeven, G.; Taelman, D.; Vermeulen, F. Computer vision-based orthophoto mapping of complex archaeological sites: The ancient quarry of itaranha (Portugal-Spain). Archaeometry 2012, 54, 1114-1129. [CrossRef]

19. Saarinen, J. Critical Sustainability: Setting the Limits to Growth and Responsibility in Tourism. Sustainability 2013, 6, 1-17. [CrossRef]

20. United Nations Environment Programme (UNEP). Making Tourism More Sustainable: A Guide for Policy Makers; UNEP: Paris, France, 2005.

21. McIntyre, G. Sustainable Tourism Development: Guide for Local Planners; World Tourism Organization: Madrid, Spain, 1993.

22. Choi, H.C.; Sirakaya, E. Measuring residents' attitude toward sustainable tourism: Development of sustainable tourism attitude scale. J. Travel Res. 2005, 43, 380-394. [CrossRef]

23. Waligo, V.M.; Clarke, J.; Hawkins, R. Implementing sustainable tourism: A multi-stakeholder involvement management framework. Tour. Manag. 2013, 36, 342-353. [CrossRef]

24. Clarke, J. A framework of approaches to sustainable tourism. J. Sustain. Tour. 1997, 5, 224-233. [CrossRef]

25. Buhalis, D. Tendencias y retos de turismo electrónico en la era de las redes sociales. Tur. y Nuevas Tecnol.-Semin. Téc. San José Costa Rica 2013, 14, 5-17.

26. Ho, C.-T.B.; Gebsombut, N. Communication Factors Affecting Tourist Adoption of Social Network Sites. Sustainability 2019, 11, 4198. [CrossRef]

27. Shen, S.; Sotiriadis, M.; Zhou, Q. Could Smart Tourists Be Sustainable and Responsible as Well? The Contribution of Social Networking Sites to Improving Their Sustainable and Responsible Behavior. Sustainability 2020, 12, 1470. [CrossRef]

28. Baggio, R.; Cooper, C. Knowledge transfer in a tourism destination: The effects of a network structure. Ser. Ind. J. 2015, 4, 145-150. [CrossRef]

29. Vecchio, P.D.; Mele, G.; Ndou, V.; Secundo, G. Creating value from Social Big Data: Implications for Smart Tourism Destinations. Inf. Process. Manag. 2018, 54, 847-860. [CrossRef]

30. eMarketer. Global Digital Travel Sales 2018. Available online: https://www.emarketer.com/content/globaldigital-travel-sales-2018 (accessed on 12 September 2019).

31. We Are Social Hootsuite. Dilgital 2020: Global Dilgital Overviwe. Available online: https://datareportal.com/ reports/digital-2020-global-digital-overview? (accessed on 8 April 2020).

32. Wang, D.; Xiang, Z.; Fesenmaier, D.R. Smartphone use in everyday life and travel. J. Travel Res. 2016, 55, 52-63. [CrossRef]

33. Garcia-Madariaga, J.; Virto, N.R.; López, M.F.B.; Manzano, J.A. Optimizing website quality: The case of two superstar museum websites. Int. J. Cult. Tour. Hosp. Res. 2019, 13, 16-36. [CrossRef]

34. Dickinson, J.E.; Ghali, K.; Cherrett, T.; Speed, C.; Davies, N.; Norgate, S. Tourism and the smartphone app: Capabilities, emerging practice and scope in the travel domain. Curr. Issues Tour. 2014, 1, 84-101. [CrossRef]

35. iResearch. China Online Travel Platform User Insight Report 2018. Available online: https://www.iresearch. com.cn/Detail/report?id=3225\&isfree $=0$ (accessed on 25 August 2019).

36. Hudson, S.; Thal, K. The impact of social media on the consumer decision process: Implications for tourism marketing. J. Travel Tour. Mark. 2013, 30, 156-160. [CrossRef]

37. Leung, D.; Law, R.; Van Hoof, H.; Buhalis, D. Social media in tourism and hospitality: A literature review. J. Travel Tour. Mark. 2013, 30, 3-22. [CrossRef] 
38. Sigala, M.; Christou, E.; Gretzel, U. Social Media in Travel, Tourism and Hospitality: Theory, Practice and Cases; Ashgate Publishing Limited: Surrey, UK, 2012.

39. Miah, S.J.; Vu, H.Q.; Gammack, J.; McGrath, M. A Big Data analytics method for tourist behaviour analysis. Inf. Manag. 2016, 54, 771-785. [CrossRef]

40. Seo, E.J.; Park, J.-W.; Choi, Y.J. The Effect of Social Media Usage Characteristics on e-WOM, Trust, and Brand Equity: Focusing on Users of Airline Social Media. Sustainability 2020, 12, 1691. [CrossRef]

41. Zimaitis, I.; Degutis, M.; Urbonavicius, S. Social Media Use and Paranoia: Factors That Matter in Online Shopping. Sustainability 2020, 12, 904. [CrossRef]

42. Foux, G. Consumer-generated media: Get your customers involved. Brand Strat. 2006, 8, 38-39.

43. Gretzel, U. Intelligent systems in tourism. A Social Science Perspective. Ann. Tour. Res. 2011, 38, 757-779. [CrossRef]

44. Minstry of Industry and Infoemation Technology of the People's Repulic of China. Internet and Related Services Remain Stable and Stable in January-October 2018. Available online: http://www.miit.gov.cn/ n1146312/n1146904/n1648355/c6531993/content.html (accessed on 25 November 2019).

45. JIGUANG. 2018 Q3 Mobile Internet Industry Data Report. Retrieved 26 November 2018. Available online: https://www.jiguang.cn/reports/350 (accessed on 26 November 2019).

46. Wen, Z.; Geng, X.; Ye, Y. Does the use of Wechat lead to subjective well-being?: The effect of use intensity and motivations. Cyber Psychol. Behav. Soc. Netw. 2016, 19, 587-592. [CrossRef]

47. WeChat Public Platform. Available online: https://mp.weixin.qq.com/cgi-bin/wx (accessed on 1 November 2019).

48. Li, A.F.; Zeng, Z.X.; Wu, X.M. The Analysis of the Development of Oblique Photography Technique in China. Geomat. Spat. Inf. Technol. 2014, 37, 57-59.

49. Xue, X.; Wu, C.; Sun, Z.; Wu, Y.; Xiong, N. Vegetation Greening for Winter Oblique Photography Using Cycle-Consistence Adversarial Networks. Symmetry 2018, 10, 294. [CrossRef]

50. Harwin, S.; Lucieer, A.; Osborn, J. The Impact of the Calibration Method on the Accuracy of Point Clouds Derived Using Unmanned Aerial Vehicle Multi-View Stereopsis. Remote Sens. 2015, 7, 11933-11953. [CrossRef]

51. Lin, H.; Shen, X.D. Pingtan County Local Chronicles Compilation Committee. In Pingtan County Records, 1st ed.; Fang Zhi Publishing House: Beijing, China, 2010; pp. 667-671.

52. Schiffman, L.G.; Kanuk, L.L.; Wisenblit, J. Consumer Behaviour, 10th ed.; Prentice Hall: Upper Saddle River, NJ, USA, 2010.

53. Solomon, M.R. The missing link: Surrogate consumers in the marketing chain. J. Mark. 1986, 50, $208-218$. [CrossRef]

54. Stone, M.J. Deciding not to choose: Delegation to social surrogates in tourism decisions. Tour. Manag. 2016, 57, 168-179. [CrossRef]

55. Noti, E. Web 2.0 and its influence in the tourism sector. Eur. Sci. J. 2013, 9, 115-123.

56. Királ'ová, A.; Pavlíčeka, A. Development of social media strategies in tourism destination. Procedia Soc. Behav. Sci. 2015, 175, 358-366. [CrossRef]

57. Chevalier, J.A.; Mayzlin, D. The Effect of Word of Mouth on Sales: Online Book Reviews. J. Mark. Res. 2006, 43, 345-354. [CrossRef]

58. Duan, W.; Gu, B.; Whinston, A.B. Do online reviews matter?-An empirical investigation of panel data. Decis. Support Syst. 2008, 45, 1007-1016. [CrossRef]

59. Forman, C.; Ghose, A.; Wiesenfeld, B. Examining the Relationship between Reviews and Sales: The Role of Reviewer Identity Disclosure in Electronic Markets. Inf. Syst. Res. 2008, 19, 291-313. [CrossRef]

60. Stickdorn, M. Tourism and service design thinking: Who learns from whom? Touchpoint 2012, 4, 58-61.

61. Penguin Intelligence. China Tourism APP Market Full Data Report. Available online: http://www.199it.com/ archives/519529.html (accessed on 25 November 2018).

62. Geser, G.; Markus, M. Prosumer im Tourismus; ITD-Verlag: Hamburg, Germany, 2008.

63. Egger, R. Grundlagen des Etourism-Informations- und Kommunikations-Technologien im Tourismus; Shaker Verlag: Aachen, Germany, 2005.

64. Clatworthy, S. Bridging the gap between brand strategy and customer experience. Manag. Serv. Qual. Int. J. 2012, 22, 108-127. [CrossRef] 
65. Stickdorn, M.; Zehrer, A. Service design in tourism: Customer experience driven destination management. In Proceedings of the First Nordic Conference on Service Design and Service Innovation, DeThinking Service-ReThinking-Design, Oslo, Norway, 24-26 November 2009; Linköping University Electronic Press: Linköping, Sweden, 2012.

66. Li, Y.; Hu, C.; Huang, C.; Duan, L. The concept of smart tourism in the context of tourism information services. Tour. Manag. 2016, 58, 293-300. [CrossRef] 